\title{
Crystal growth and structural analysis of zirconium sulphoselenide single crystals
}

\author{
K R PATEL*, R D VAIDYA, M S DAVE ${ }^{\dagger \dagger}$ and S G PATEL ${ }^{\dagger}$ \\ Ashok and Rita Patel Institute of Integrated Study and Research in Biotechnology and Allied Sciences, \\ New Vallabh Vidyanagar 388 121, India \\ ${ }^{\dagger}$ N.V. Patel College of Pure and Applied Sciences, Vallabh Vidyanagar 388 120, India \\ ${ }^{\dagger \dagger}$ Department of Physics, Sardar Patel University, Vallabh Vidyanagar 388 120, India
}

MS received 8 October 2007; revised 2 March 2008

\begin{abstract}
A series of zirconium sulphoselenide $\left(\mathrm{ZrS}_{x} \mathrm{Se}_{3-x}\right.$, where $\left.x=0,0 \cdot 5,1,1 \cdot 5,2,2 \cdot 5,3\right)$ single crystals have been grown by chemical vapour transport technique using iodine as a transporting agent. The optimum condition for the growth of these crystals is given. The stoichiometry of the grown crystals were confirmed on the basis of energy dispersive analysis by X-ray (EDAX) and the structural characterization was accomplished by $X$-ray diffraction (XRD) studies. The crystals are found to possess monoclinic structure. The lattice parameters, volume, particle size and $X$-ray density have been carried out for these crystals. The effect of sulphur proportion on the lattice parameter, unit cell volume and $\mathrm{X}$-ray density in the series of $\mathrm{ZrS}_{x} \mathrm{Se}_{3-x}$ single crystals have been studied and found to decrease in all these parameters with rise in sulphur proportion. The grown crystals were examined under optical zoom microscope for their surface topography study. Hall effect measurements were carried out on grown crystals at room temperature. The negative value of Hall coefficient implies that these crystals are $n$-type in nature. The conductivity is found to decrease with increase of sulphur content in the $\mathrm{ZrS}_{x} \mathrm{Se}_{3-x}$ series. The electrical resistivity parallel to $c$-axis as well as perpendicular to $c$-axis have been carried out in the temperature range 303-423 $\mathrm{K}$. The results obtained are discussed in detail.
\end{abstract}

Keywords. $\quad \mathrm{ZrS}_{x} \mathrm{Se}_{3-x}$ single crystal; EDAX; XRD.

\section{Introduction}

The transition metal trichalcogenide, $\mathrm{MX}_{3}$ (where $\mathrm{M}=\mathrm{Zr}$, $\mathrm{Hf}$, Ta and $\mathrm{X}=\mathrm{S}$, Se, Te) compounds crystallize monoclinically and grow as fibrous ribbons. The linear chain of metal atoms located at the centre of distorted prisms show trigonal faces and form isolated columns. These single crystals belong to the $P 2_{1} / m$ space group (Furuseth et al 1975). The linear chain of metal atoms is parallel to the crystallographic $b$-axis, which is the growth axis. Six chalcogen atoms surround each metal atom forming distorted trigonal prisms. Resistivity, Hall coefficient and thermo electric power measurement along the chain axis for $\mathrm{ZrS}_{3}$ single crystal have been carried out in the temperature range from 200-400 K (Ikari et al 1983).

The crystal structure of $\mathrm{ZrSe}_{3}$ is shown in figure 1 . There are two formula units per cell each associated with a trigonal prismatic column running along the $t_{3}$ axis. Other trichalcogenides exhibit similar columns, but the prisms are rearranged in a more complex manner reflecting in influence of metal-metal bonding and/or ionic interaction (Wilson 1979).

\footnotetext{
*Author for correspondence (kparibas@yahoo.co.in)
}

The $\mathrm{ZrS}_{3}$ and $\mathrm{ZrSe}_{3}$ exhibit a layer like semiconducting behaviour (Sourisseau and Mathey 1981). In the anisotropic $\mathrm{ZrS}_{3-x} \mathrm{Se}_{x}$ compounds, the velocity of acoustic wave propagating in a direction parallel to the fibres decreases linearly as the selenium content increases for $0<x<2$ (Poirier and Seguin 1985). At lower temperature the measurements for $\mathrm{ZrSe}_{3}$ can be analysed in terms of the familiar Debye $T^{3}$ law yielding characteristic Debye temperature. At absolute zero, $\theta_{\mathrm{D}}=110 \pm 2 \mathrm{~K}$ is in satisfactory arrangement with the value extracted from the available experimentally sound velocities. In contrast, the $\mathrm{ZrS}_{3}$ measurement does not behave according to the Debye law (Provencher et al 1986).

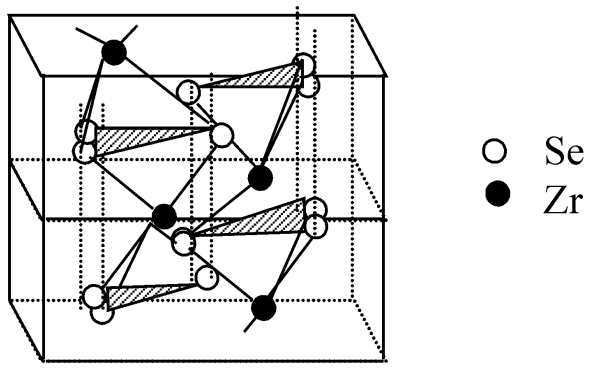

Figure 1. The crystal structure of $\mathrm{ZrSe}_{3}$ single crystals. 
Table 1. Growth parameters of zirconium sulphoselenide single crystal grown using chemical vapour transport technique.

\begin{tabular}{lcccccc}
\hline & & & \multicolumn{3}{c}{ Physical characteristics of the crystals } \\
\cline { 4 - 7 } Sample & $\begin{array}{c}\text { Reaction } \\
\text { temperature }\end{array}$ & $\begin{array}{c}\text { Growth } \\
\text { temperature }\end{array}$ & $\begin{array}{c}\text { Growth } \\
\text { time (h) }\end{array}$ & $\begin{array}{c}\text { Plate area } \\
\left(\mathrm{mm}^{2}\right)\end{array}$ & $\begin{array}{c}\text { Thickness } \\
(\mathrm{mm})\end{array}$ & $\begin{array}{c}\text { Colour and } \\
\text { appearance }\end{array}$ \\
\hline $\mathrm{ZrSe}_{3}$ & 873 & 1023 & 370 & 20 & 0.09 & Gray shining \\
$\mathrm{ZrS}_{0.5} \mathrm{Se}_{2.5}$ & 893 & 1043 & 370 & 15 & 0.09 & Black shining \\
$\mathrm{ZrSSe}_{2}$ & 913 & 1063 & 370 & 13 & 0.08 & Black shining \\
$\mathrm{ZrS}_{1.5} \mathrm{Se}_{1.5}$ & 933 & 1083 & 370 & 15 & 0.07 & Silver black shining \\
$\mathrm{ZrS}_{2} \mathrm{Se}$ & 953 & 1103 & 370 & 11 & 0.07 & Red shining \\
$\mathrm{ZrS}_{2.5} \mathrm{Se}_{0.5}$ & 973 & 1123 & 370 & 10 & 0.06 & Red shining \\
$\mathrm{ZrS}_{3}$ & 993 & 1143 & 370 & 10 & 0.06 & Red shining \\
\hline
\end{tabular}

$\mathrm{ZrS}_{x} \mathrm{Se}_{3-x}$ series exhibit continuous regions of solid solubility. Diffuse reflectance measurement shows that $\mathrm{ZrS}_{3-x} \mathrm{Se}_{x}$ exhibit semiconduction (Brattas and Kjekshus 1972). Thermoreflectance spectra of $\mathrm{ZrS}_{3-x} \mathrm{Se}_{x}$ single crystals have been measured at $50 \mathrm{~K}$. The thermoreflectance spectra of $\mathrm{ZrS}_{3}$ and $\mathrm{ZrSe}_{3}$ are discussed through direct and indirect exciton transition (Provencher et al 1988). A detailed study of the valence band by synchrotron radiation photoemission spectroscopy and the existence of paired-anion ligands in zirconium trichalcogenides had been demonstrated (Margaritondo et al 1980). The direct band gap between occupied and unoccupied states at $t$ is $2.7 \mathrm{eV}$ and at $A 1.8 \mathrm{eV}$, however, an indirect band gap is present from the top of the valence band at $t$ to the bottom of the conduction band at $A 1.3 \mathrm{eV}$ (Prodam et al 2001).

The X-ray diffraction pattern of $\mathrm{ZrS}_{3}$ shows the monoclinic structure with lattice constants $a=5.13 \AA, b=3.61 \AA$, $c=9.01 \AA$ and $\beta=97.13^{\circ}$ (Huang et al 2004). The development of stresses by variation in high temperature of the two zones result into slip lines and leads to generation of favourable screw dislocation sites for $\mathrm{ZrS}_{3}$ single crystals (Patel et al 1996).

Looking to the importance of these compounds, we have grown single crystals of zirconium sulphoselenide by chemical vapour transport technique using iodine as a transporting agent in order get single crystals with maximum dimensions. We have also carried out the structural properties of $\mathrm{ZrS}_{x} \mathrm{Se}_{3-x}$ (where $x=0,0.5,1,1.5,2,2.5$ and 3 ). The results thus obtained have been discussed in this paper.

\section{Experimental}

The single crystals of zirconium sulphoselenide $\left(\mathrm{ZrS}_{x} \mathrm{Se}_{3-x}\right)$ have been grown by chemical vapour transport technique with iodine as a transporting agent. Highly pure compounds of zirconium powder (97\% make: Riedel-de Haen), sulphur (99.97\% make: Chiti-Chem Corporation, India) and selenide (99.98\% Make: Aldrich, USA) were taken in a stoichiometric proportion in a quartz ampoule for charge preparation. It was evacuated to a pressure of $10^{-5}$ torr and then sealed. This sealed ampoule was introduced into a two-zone furnace at a constant reaction temperature to obtain the charge. During the synthesis the temperature was slowly increased up to $1073 \mathrm{~K}$ with $10 \mathrm{~K} / \mathrm{h}$. The ampoule was kept at this temperature for 4 days. Then the furnace was slowly cooled $(20 \mathrm{~K} / \mathrm{h})$ and brought to room temperature. The resulting brown and/or reddish charge was obtained in the ampoule. This charge was crushed and transferred to other quartz ampoule. The iodine $(2 \mathrm{mg} / \mathrm{cc})$ as a transporting agent was taken in glass capillaries. The capillaries were sealed and placed in the quartz ampoule before evacuation. It was also evacuated up to a pressure of $10^{-5}$ torr. This ampoule was placed in a two-zone horizontal furnace for 10 days with a temperature gradient as shown in table 1 . Then the furnace was cooled up to room temperature with a rate of $10 \mathrm{~K} / \mathrm{h}$. The entire material got converted into the form of crystals at the cooler end of the ampoule. The grown crystals were collected after breaking the ampoule. The optimum conditions and growth parameters for as grown crystals are shown in table 1.

The chemical composition of the as grown crystals was confirmed with the help of energy dispersive analysis by X-ray (EDAX). The EDAX spectra of all crystals are shown in figure 2. The stoichiometric proportion of as grown crystals as well as the EDAX results are shown in table 2. Close examination of the surface composed of layers helps a great deal in understanding the mechanism by which a crystal can grow. Therefore, it was thought worthwhile to make surface characterization of these grown crystals by optical microscopy. The surface microstructure of as grown crystals were examined by computer aided optical zoom microscope (Make: Carl Zeiss, Model Axiotech 100HD). The surface microstructure on the face of as grown crystals are shown in figure 3, which shows layered surface structures.

For X-ray diffraction (XRD) study, several small crystals were finely ground with the help of an agate mortar and filtered through 106-micron sieve to obtain grains of nearly equal size. The X-ray diffractograms were taken 

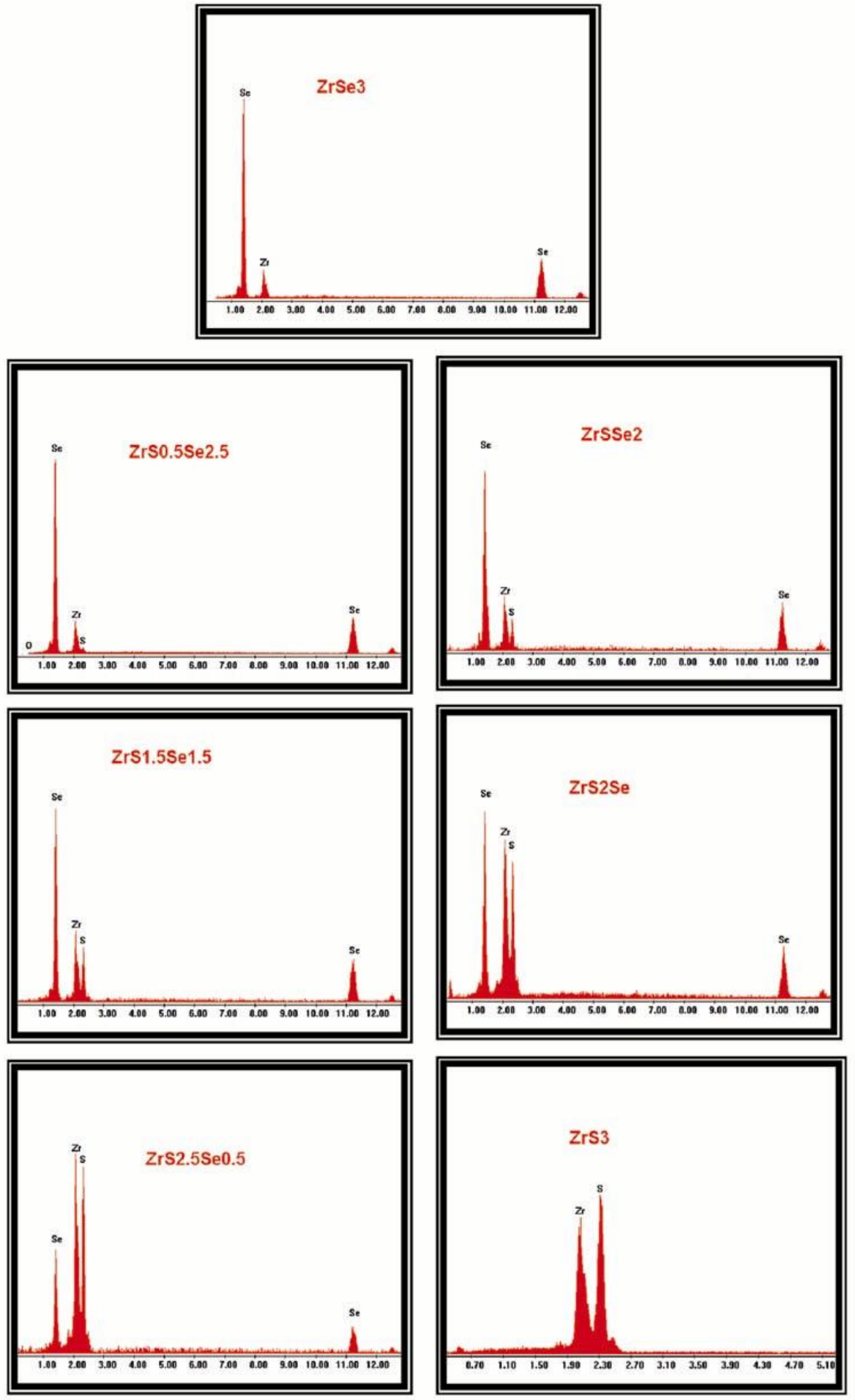

Figure 2. The EDAX spectra of zirconium sulphoselenide single crystals.

with Philips X-ray diffractometer (model: PW1820) employing $\mathrm{CuK}_{\alpha}$ radiation.

The room temperature resistivity of all crystals was determined using van der Pauw's technique. The Hall effect measurements were carried out to determine Hall coefficient, mobility and carrier concentration. The electrical resistivity measurements parallel to $c$-axis were carried out using the experimental set-up designed by our University Scientific Instrumentation Centre. The crystal was mounted on a sample holder, which was then in- 

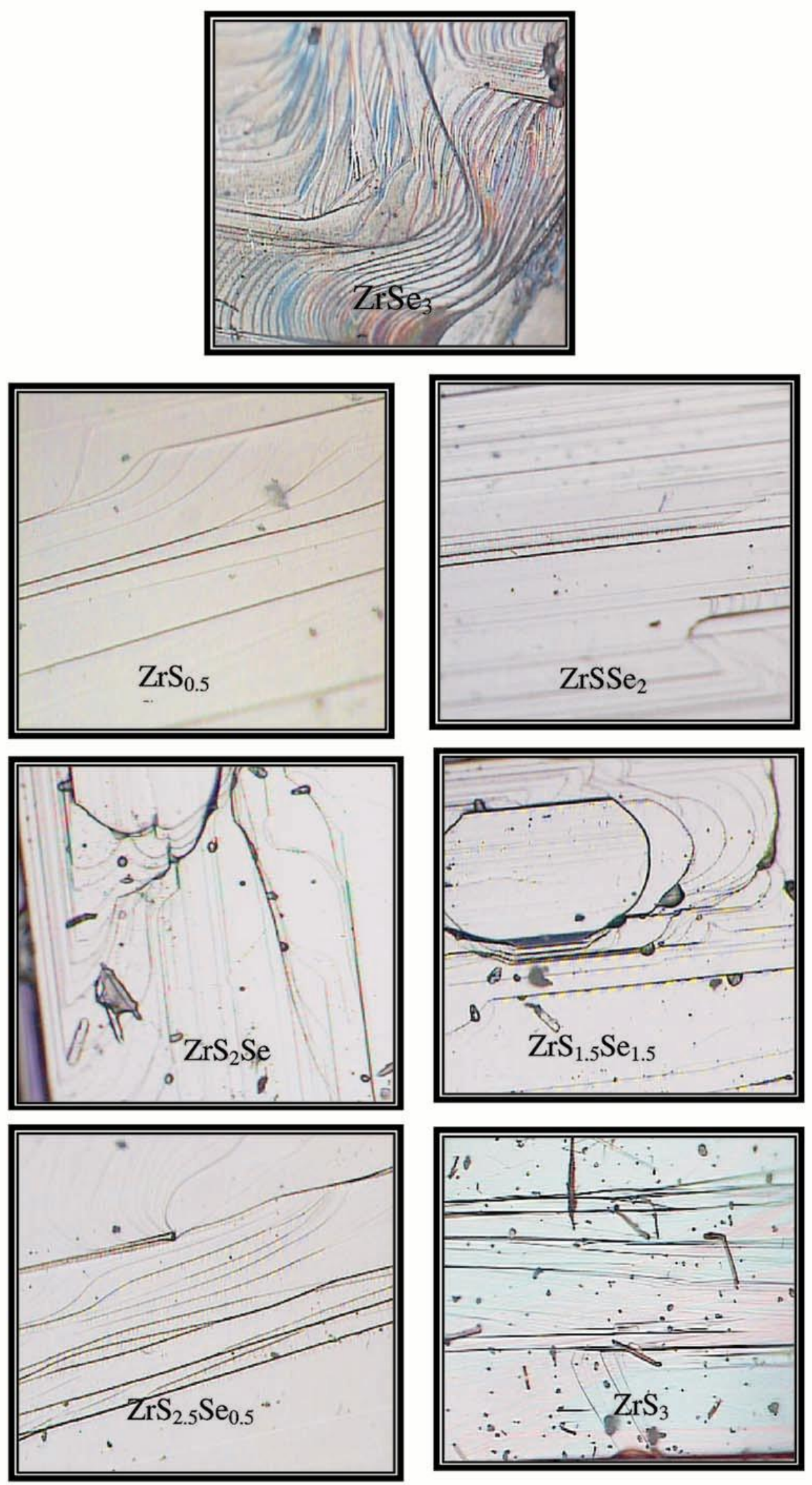

Figure 3. The microstructure of zirconium sulphoselenide single crystals. 
Crystal growth and structural analysis of zirconium sulphoselenide single crystals

Table 2. EDAX data for zirconium sulphoselenide single crystals.

\begin{tabular}{|c|c|c|c|c|c|c|}
\hline \multirow[b]{2}{*}{ Sample } & \multicolumn{3}{|c|}{ Stoichiometric proportion (wt\%) } & \multicolumn{3}{|c|}{ EDAX results (wt\%) } \\
\hline & $\mathrm{Zr}$ & $\mathrm{S}$ & $\mathrm{Se}$ & $\mathrm{Zr}$ & $\mathrm{S}$ & $\mathrm{Se}$ \\
\hline $\mathrm{ZrSe}_{3}$ & $27 \cdot 80$ & - & $72 \cdot 20$ & $25 \cdot 26$ & - & $74 \cdot 74$ \\
\hline $\mathrm{ZrS}_{0.5} \mathrm{Se}_{2.5}$ & $29 \cdot 94$ & $5 \cdot 26$ & $64 \cdot 80$ & $27 \cdot 78$ & $3 \cdot 45$ & $68 \cdot 67$ \\
\hline $\mathrm{ZrSSe}_{2}$ & $32 \cdot 44$ & 11.40 & $56 \cdot 16$ & $31 \cdot 19$ & 7.96 & $60 \cdot 86$ \\
\hline $\mathrm{ZrS}_{1.5} \mathrm{Se}_{1.5}$ & $35 \cdot 39$ & $18 \cdot 66$ & $45 \cdot 95$ & $34 \cdot 22$ & $14 \cdot 67$ & $51 \cdot 11$ \\
\hline $\mathrm{ZrS}_{2} \mathrm{Se}$ & 38.90 & $27 \cdot 40$ & $33 \cdot 70$ & 45.41 & $24 \cdot 15$ & $30 \cdot 45$ \\
\hline $\mathrm{ZrS}_{2.5} \mathrm{Se}_{0.5}$ & $43 \cdot 26$ & $38 \cdot 02$ & $18 \cdot 72$ & $50 \cdot 43$ & $30 \cdot 09$ & 19.48 \\
\hline $\mathrm{ZrS}_{3}$ & $48 \cdot 67$ & $53 \cdot 3$ & - & $48 \cdot 65$ & $51 \cdot 35$ & - \\
\hline
\end{tabular}
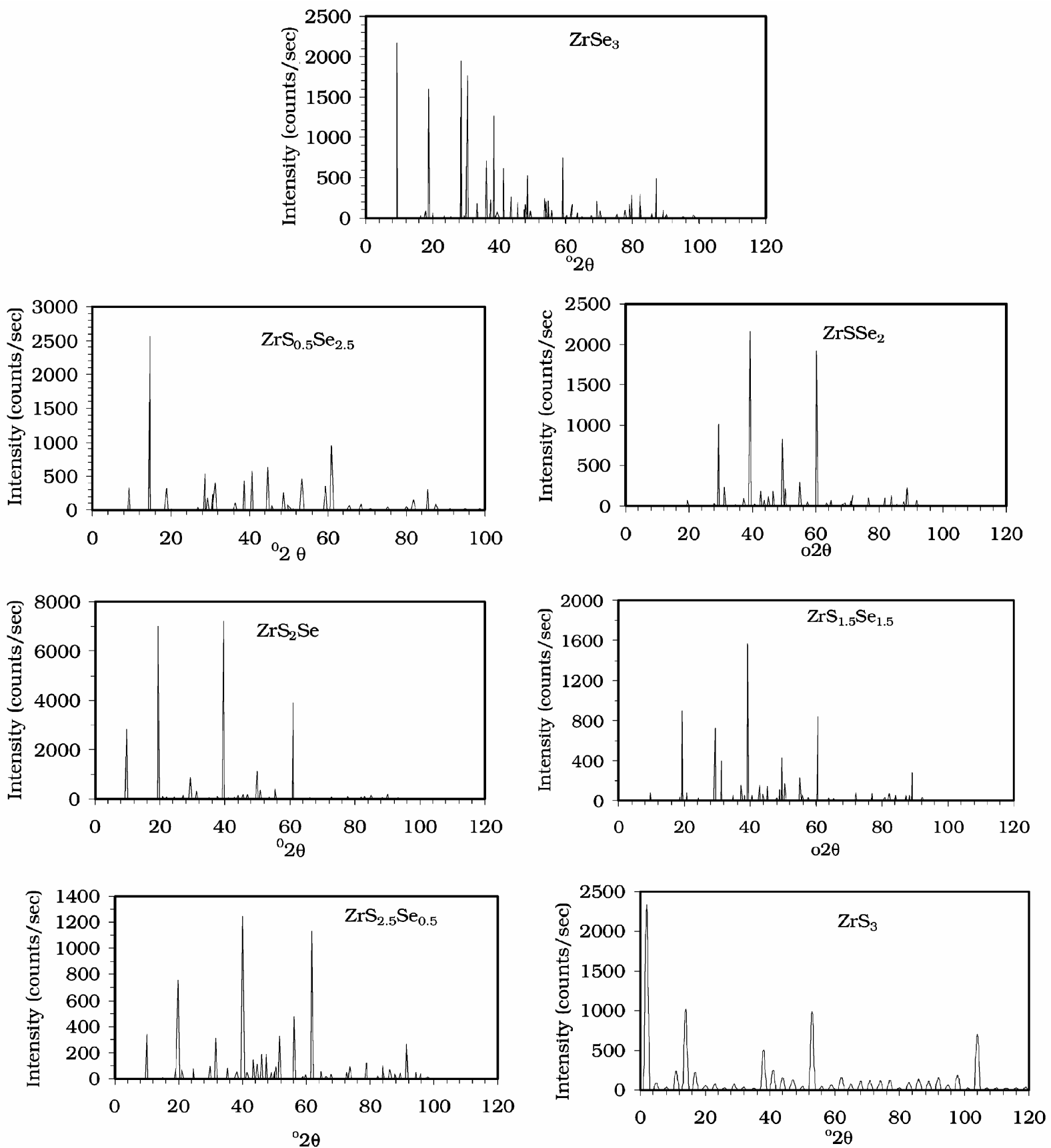

Figure 4. The X-ray diffractogram for zirconium sulphoselenide single crystals. 
Table 3. Crystallographic data of zirconium sulphoselenide single crystals.

\begin{tabular}{lcccccc}
\hline Sample & $a(\AA)$ & $b(\AA)$ & $c(\AA)$ & $\beta$ & $V(\AA)^{3}$ & $\begin{array}{c}\text { X-ray density, } \\
\rho(\mathrm{g} / \mathrm{cc})\end{array}$ \\
\hline $\mathrm{ZrSe}_{3}$ & 5.45 & 3.787 & 9.45 & 97.46 & 193.5 & 5.63 \\
$\mathrm{ZrS}_{0.5} \mathrm{Se}_{2.5}$ & 5.38 & 3.73 & 9.39 & 97.44 & 185.54 & 5.42 \\
$\mathrm{ZrSSe}_{2}$ & 5.30 & 3.68 & 9.28 & 97.42 & 179.21 & 5.21 \\
$\mathrm{ZrS}_{1.5} \mathrm{Se}_{1.5}$ & 5.23 & 3.64 & 9.21 & 97.38 & 173.92 & 4.92 \\
$\mathrm{ZrS}_{2} \mathrm{Se}$ & 5.18 & 3.63 & 9.16 & 97.34 & 170.83 & 4.55 \\
$\mathrm{ZrS}_{2.5} \mathrm{Se}_{0.5}$ & 5.13 & 3.61 & 9.09 & 97.31 & 166.57 & 4.32 \\
$\mathrm{ZrS}_{3}$ & 5.08 & 3.58 & 8.98 & 97.28 & 162.06 & 3.84 \\
\hline
\end{tabular}

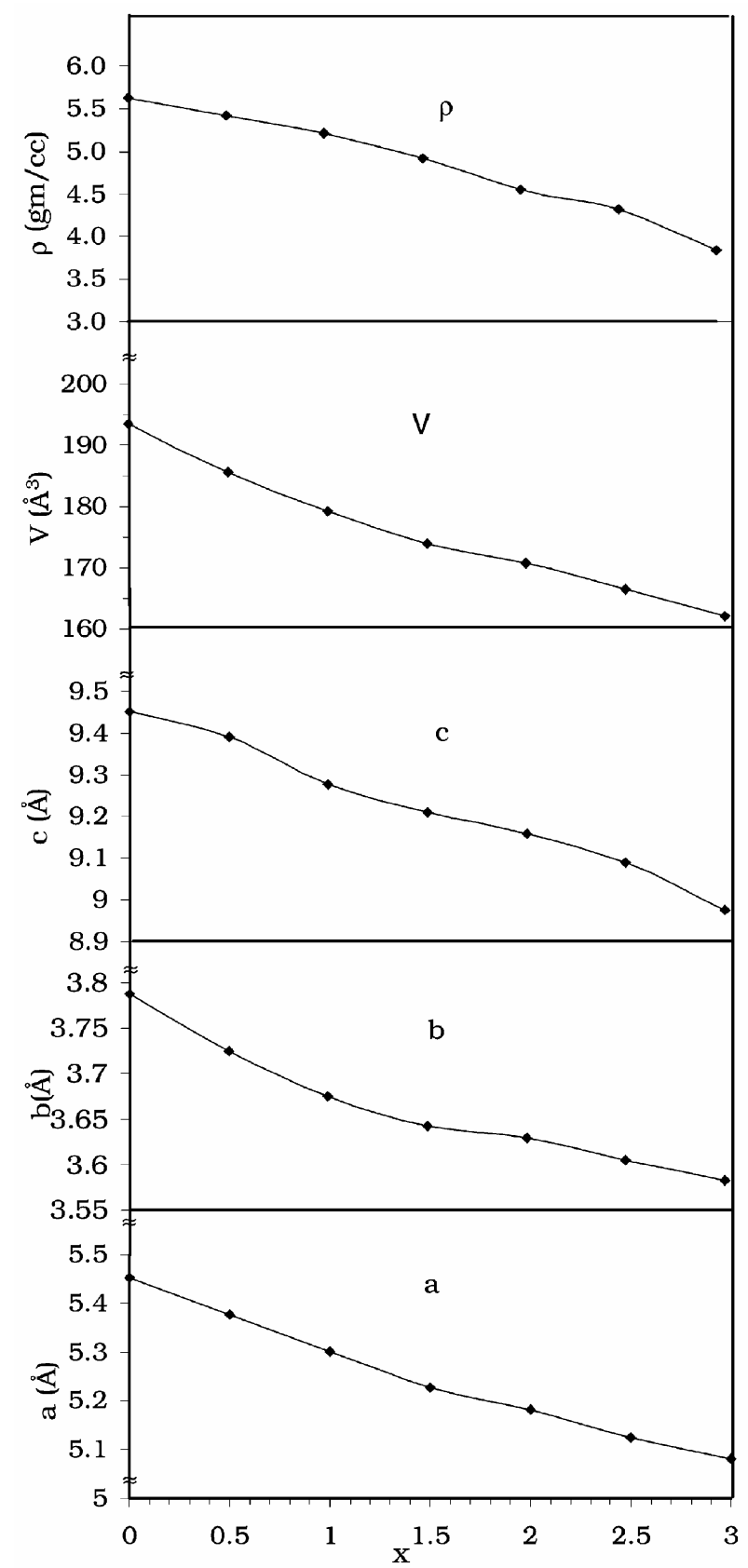

Figure 5. The graph of lattice parameter (a, b and c), X-ray density $(\rho)$ and volume $(V)$ vs composition, $X$, in series $\mathrm{ZrS}_{x} \mathrm{Se}_{3-x}$ single crystals. serted into a sample chamber. The temperature of the crystals was increased by introducing the sample chamber into a vertical single zone furnace.

\section{Results and discussion}

The needle shaped, black or radish shining layered single crystals of zirconium sulphoselenide were successfully grown by chemical vapour transport technique. From table 2, the stoichiometry of as grown crystals is nearly preserved. The X-ray diffractogram obtained for $\mathrm{ZrS}_{x} \mathrm{Se}_{3-x}$ $(x=0,0.5,1,1.5,2,2.5$ and 3$)$ are shown in figure 4 . The pattern consists of well-defined sharp diffraction peaks, indicating good crystallinity of the specimen.

The lattice parameters, unit cell volume $(V)$ and X-ray density $(\rho)$ were obtained from the X-ray diffractogram data for as grown crystals as shown in table 3 . The obtained values of as grown samples possess monoclinic layered structure with space group $P 2_{1} / \mathrm{m}$. In order to get an idea about the grain size distribution and particle size for each sample, calculation was done using Scherrer's formula given by Srivastava and Avasthi (1986)

$$
t=\frac{K \lambda}{\beta \cos \theta},
$$

where $t$ is the crystallite size as measured perpendicular to the reflecting plane, $K$ the Scherrer constant whose value is taken to be unity assuming the particles to be spherical, $\lambda$ the wavelength of $\mathrm{X}$-ray radiation, $\beta$ the half intensity which was measured in radians and $\theta$ the Bragg angle. The $(h k l)$ values corresponding to prominent reflection $d$-values, half width, peak intensities and particle size for $\mathrm{ZrS}_{x} \mathrm{Se}_{3-x}$ crystals are shown in table 4 .

Systematic changes in the structural parameters could be of importance in obtaining an insight. Extraction of such chemical insights depends strongly on structureproperty correlations, and the most basic of these is the changes in lattice parameters. The quality of a solid solution is usually examined from the composition-dependent lattice parameter changes in terms of the empirical Vegard (1921) law. This law states that in the absence of strong electronic effects the variation of lattice parameters is linear with composition in a true three-dimensional 

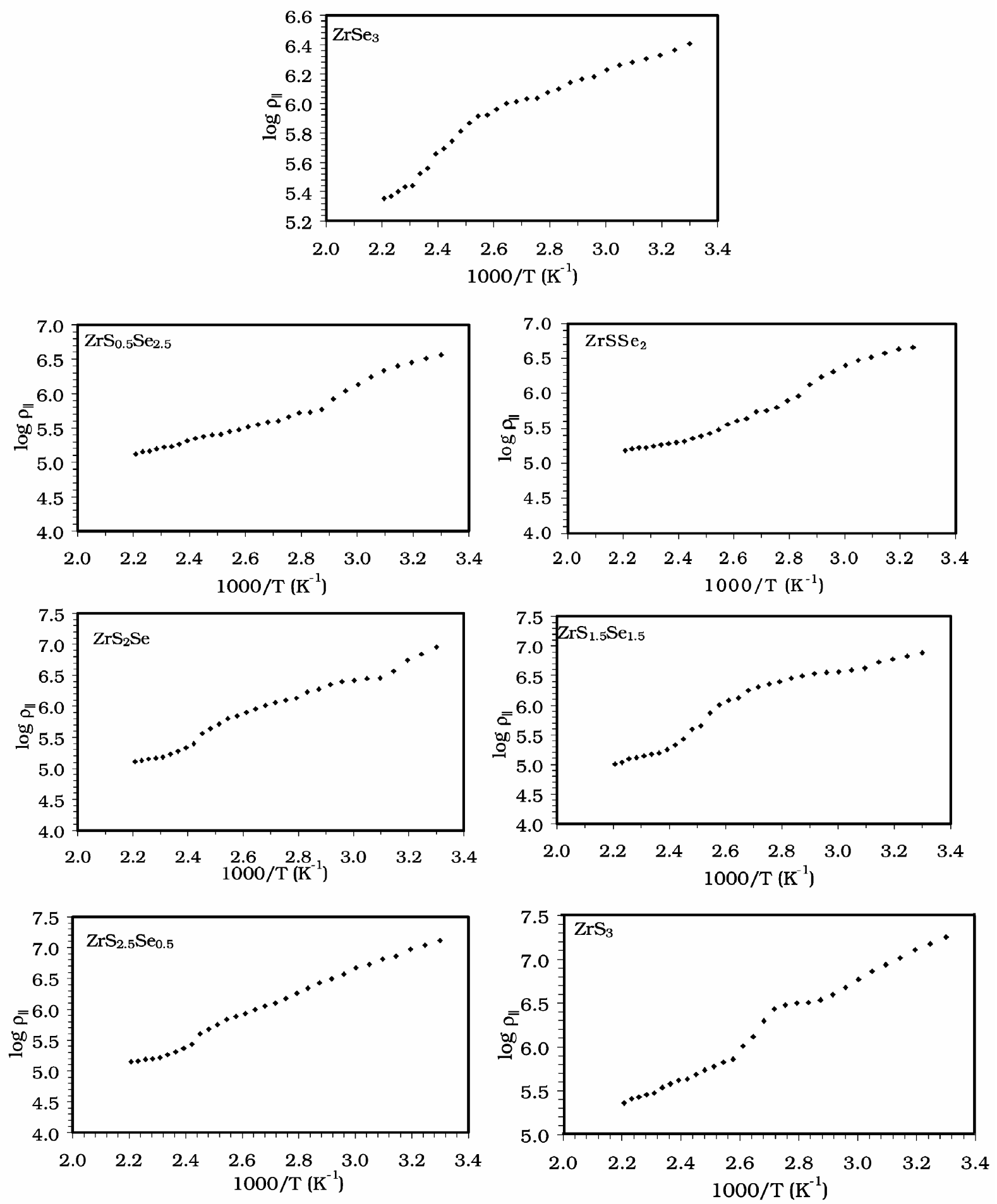

Figure 6. The variation of resistivity (parallel to $c$-axis) with reciprocal of temperature.

solid solution. The Vegard law is a consequence of the way a solid solution reduces strain by an expansion (or compression) when species of different sizes are involved. In two-dimensional system, the non-Vegard law behaviour (nonlinear changes in lattice parameter with composition has been well documented (Vegard and Dale
1928; Whittingham and Gamble 1975)). The variation of lattice parameter with composition, $x$, is shown in figure 5 . In figure 5 , the values of lattice parameter decreases with increase in sulphur proportion (composition). Figure 5 shows deviation from Vegard's law (REF) in respect of the axes $a$ and $c$ having a similar character 
Table 4. The $(h k l)$ values corresponding to prominent reflection $d$-values, peak width, peak intensity and particle size for zirconium sulphoselenide single crystals.

\begin{tabular}{|c|c|c|c|c|c|}
\hline Sample & $h k l$ & $d$-spacing & Peak width, $2 \theta$ & Peak intensity (counts/s) & Particle size $(\AA)$ \\
\hline $\mathrm{ZrSe}_{3}$ & $\begin{array}{l}035 \\
015 \\
111 \\
001\end{array}$ & $\begin{array}{l}1.0425 \\
1.6927 \\
2.9309 \\
9.4393\end{array}$ & $\begin{array}{l}95 \cdot 27 \\
54 \cdot 14 \\
30 \cdot 47 \\
9 \cdot 3614\end{array}$ & $\begin{array}{r}16 \cdot 16 \\
200 \cdot 33 \\
1767 \cdot 13 \\
2162 \cdot 29\end{array}$ & $\begin{array}{l}238 \cdot 16 \\
576 \cdot 69 \\
665 \cdot 29 \\
858 \cdot 72\end{array}$ \\
\hline $\mathrm{ZrS}_{0.5} \mathrm{Se}_{2.5}$ & $\begin{array}{l}502 \\
123 \\
200 \\
101\end{array}$ & $\begin{array}{l}1.0154 \\
1.5182 \\
2.6565 \\
4.4021\end{array}$ & $\begin{array}{l}98 \cdot 67 \\
60 \cdot 97 \\
33 \cdot 71 \\
20 \cdot 15\end{array}$ & $\begin{array}{r}32.97 \\
949.83 \\
12.63 \\
17.03\end{array}$ & $\begin{array}{l}281 \cdot 41 \\
331 \cdot 03 \\
223 \cdot 56 \\
434 \cdot 62\end{array}$ \\
\hline $\mathrm{ZrSSe}_{2}$ & $\begin{array}{l}217 \\
220 \\
113 \\
110\end{array}$ & $\begin{array}{l}1.0723 \\
1.5339 \\
2 \cdot 1195 \\
3.0446\end{array}$ & $\begin{array}{l}93 \cdot 83 \\
60 \cdot 29 \\
42 \cdot 62 \\
29 \cdot 30\end{array}$ & $\begin{array}{r}73 \cdot 38 \\
1917 \cdot 24 \\
184 \cdot 03 \\
1017 \cdot 74\end{array}$ & $\begin{array}{l}469 \cdot 81 \\
499.97 \\
456 \cdot 68 \\
442.31\end{array}$ \\
\hline $\mathrm{ZrS}_{1.5} \mathrm{Se}_{1.5}$ & $\begin{array}{l}027 \\
015 \\
210 \\
100\end{array}$ & $\begin{array}{l}1 \cdot 0816 \\
1.6656 \\
2 \cdot 2234 \\
5 \cdot 1837\end{array}$ & $\begin{array}{l}90 \cdot 83 \\
55 \cdot 09 \\
40 \cdot 54 \\
17 \cdot 09\end{array}$ & $\begin{array}{r}12 \cdot 62 \\
226 \cdot 98 \\
53 \cdot 48 \\
10 \cdot 10\end{array}$ & $\begin{array}{l}365 \cdot 74 \\
579 \cdot 19 \\
912 \cdot 36 \\
432 \cdot 73\end{array}$ \\
\hline $\mathrm{ZrS}_{2} \mathrm{Se}$ & $\begin{array}{l}023 \\
114 \\
110 \\
001\end{array}$ & $\begin{array}{l}1.5827 \\
1.7511 \\
3.0300 \\
9.0792\end{array}$ & $\begin{array}{l}58 \cdot 24 \\
52 \cdot 19 \\
29 \cdot 38 \\
9.7336\end{array}$ & $\begin{array}{r}18.90 \\
22.97 \\
896.01 \\
2843.94\end{array}$ & $\begin{array}{l}813 \cdot 00 \\
476 \cdot 48 \\
331 \cdot 19 \\
429 \cdot 47\end{array}$ \\
\hline $\mathrm{ZrS}_{2.5} \mathrm{Se}_{0.5}$ & $\begin{array}{l}233 \\
301 \\
104 \\
012\end{array}$ & $\begin{array}{l}1.0210 \\
1.6339 \\
1.9701 \\
2.8268\end{array}$ & $\begin{array}{l}97 \cdot 95 \\
56 \cdot 25 \\
46 \cdot 03 \\
31 \cdot 62\end{array}$ & $\begin{array}{r}14.75 \\
475.37 \\
191.95 \\
312.08\end{array}$ & $\begin{array}{l}244.45 \\
472 \cdot 63 \\
464.99 \\
444.75\end{array}$ \\
\hline $\mathrm{ZrS}_{3}$ & $\begin{array}{l}134 \\
323 \\
006 \\
001\end{array}$ & $\begin{array}{l}1.0387 \\
1.1369 \\
1.4865 \\
8.9582\end{array}$ & $\begin{array}{r}95 \cdot 75 \\
85 \cdot 04 \\
62.41 \\
8.95\end{array}$ & $\begin{array}{r}39.50 \\
35.57 \\
694.95 \\
2335.05\end{array}$ & $\begin{array}{l}478.44 \\
580.51 \\
205.73 \\
859.04\end{array}$ \\
\hline
\end{tabular}

Table 5. Hall coefficient, mobility and carrier concentration of zirconium sulphoselenide single crystals.

\begin{tabular}{lccccc}
\hline Sample & $\begin{array}{c}\text { Resistivity, } \\
\rho(\Omega \cdot \mathrm{cm})\end{array}$ & $\begin{array}{c}\text { Conductivity, } \\
\sigma(\Omega / \mathrm{cm})^{-1}\end{array}$ & $\begin{array}{c}\text { Hall coefficient, } \\
R_{\mathrm{H}}\left(\mathrm{cm}^{3} / \mathrm{c}\right)\end{array}$ & $\begin{array}{c}\text { Mobility, } \\
\mu\left(\mathrm{cm}^{3} / \mathrm{Vs}\right)\end{array}$ & $\begin{array}{c}\text { Carrier concentration, } \\
N_{\mathrm{c}}(\mathrm{cm})^{-3}\end{array}$ \\
\hline $\mathrm{ZrSe}_{3}$ & $0 \cdot 67$ & 1.47 & -760 & 1121.6 & $8.21 \times 10^{15}$ \\
$\mathrm{ZrS}_{0.5} \mathrm{Se}_{2.5}$ & $0 \cdot 78$ & 1.28 & -895 & $1145 \cdot 7$ & $6.97 \times 10^{15}$ \\
$\mathrm{ZrSSe}_{2}$ & 1.20 & 0.83 & -1310 & $1088 \cdot 9$ & $4.76 \times 10^{15}$ \\
$\mathrm{ZrS}_{1.5} \mathrm{Se}_{1.5}$ & 1.68 & 0.59 & -1970 & 1072.6 & $3.16 \times 10^{15}$ \\
$\mathrm{ZrS}_{2} \mathrm{Se}_{\mathrm{ZrS}_{2.5} \mathrm{Se}_{0.5}}^{2 \cdot 85}$ & 0.35 & -3250 & $1138 \cdot 2$ & $1.92 \times 10^{15}$ \\
$\mathrm{ZrS}_{3}$ & 8.39 & 0.15 & -7520 & $1123 \cdot 3$ & $0.83 \times 10^{15}$ \\
\hline
\end{tabular}

for a given axis of the $\mathrm{ZrS}_{x} \mathrm{Se}_{3-x}$ phases. The origin of these findings is probably associated with the systematic variation in the eight-position parameter of the $\mathrm{ZrSe}_{3}$ type structure which are likely to occur as functions of composition within the homogeneity ranges.

The Hall coefficient, carrier concentration and mobility of as grown crystals are listed in table 5 . The negative sign of Hall coefficients suggests that all crystals are of $n$ type. The variation of electrical resistivity parallel as well as perpendicular to $c$-axis with temperature are shown in figures 6 and 7. The resistivity of both normal as well as along the basal plane decreases with increase in tempe- rature which indicates the semiconducting behaviour of the as grown crystals. The resistivity increases with increase in the sulphur content. In all the cases, the resistivity parallel to $c$-axis is higher than the resistivity perpendicular to $c$-axis.

\section{Conclusions}

The growth of needle-shaped zirconium sulphoselenide takes place through vapour phase having iodine as transporting agent. 

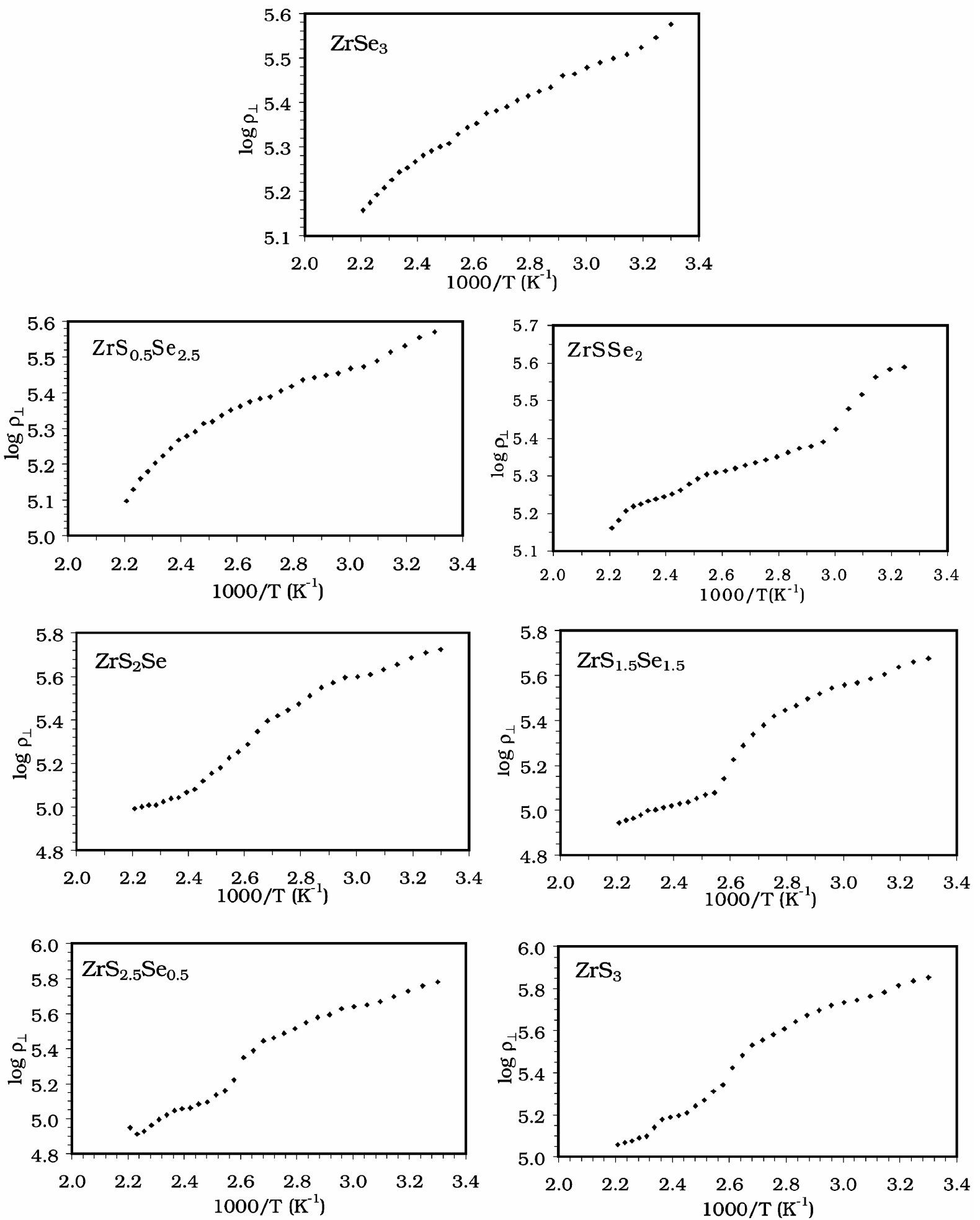

Figure 7. The variation of resistivity (perpendicular to $c$-axis) with reciprocal of temperature.

In $\mathrm{ZrSe}_{3}$ the metal-metal atomic distance is $3.74 \AA$ and is longer than the $3.62 \AA$ of $\mathrm{ZrS}_{3}$. This gives rise to a narrow conduction band in terms of energy and a larger carrier effective mass. Thus the mobility of $\mathrm{ZrSe}_{3}$ becomes smaller than that of $\mathrm{ZrS}_{3}$.

\section{References}

Brattas L and Kjekshus A 1972 Acta Chem. Scand. 26 3441

Furuseth S, Brattas L and Kjekshus A 1975 Acta Chem. Scand. A29 623 
Huang L, Tang K, Yang Q, Shen G and Jia S 2004 Mater. Res. Bull. 391083

Ikari T, Provencher R, Jandl S and Aubin M 1983 Solid State Commun. 45113

Margaritondo G, Katnani A D and Stoffel N G 1980 Solid State Commun. 35301

Patel S G, Agrawal M K and Arora S K 1996 Cryst. Res. Technol. 31851

Poirier M and Seguin P E 1985 Solid State Commun. 54 375

Prodam A, Marinkovi V, Jug N, van Midden $\mathrm{H}$, Bohm $\mathrm{H}$, Bolwell F and Bemett J 2001 Surf. Sci. 482-485 1383
Provencher R, Ayuache C, Jandl S and Gerin J 1986 Solid State Commun. 59553

Provencher R, Gagnon R, Jandl S and Aubin M 1988 J. Phys. C: Solid State Phys. 21615

Sourisseau C and Mathey Y 1981 Chem. Phys. 63143

Srivastava S K and Avasthi B N 1986 J. Less Common Metals 12485

Vegard L 1921 Z. Phys. 517

Vegard L Z and Dale H Z 1928 Krist. 67148

Wilson J A 1979 Phys. Rev. B19 6456

Whittingham M S and Gamble F R 1975 Mater. Res. Bull. 10 363 